\title{
The role of EBV in the pathogenesis of Burkitt's Lymphoma: an Italian hospital based survey
}

\author{
Giuseppe Pannone ${ }^{1 \dagger}$, Rosanna Zamparese ${ }^{2 \dagger}$, Mirella Pace ${ }^{1 \dagger}$, Maria Carmela Pedicillo $^{1}$, Simona Cagiano ${ }^{1 \dagger}$, \\ Pasquale Somma ${ }^{3 \dagger}$, Maria Elena Errico ${ }^{4 \dagger}$, Vittoria Donofrio ${ }^{4 \dagger}$, Renato Franco ${ }^{5 \dagger}$, Annarosaria De Chiara ${ }^{5 \dagger}$, \\ Gabriella Aquino ${ }^{5 \dagger}$, Paolo Bucci ${ }^{6 \dagger}$, Eduardo Bucci ${ }^{6+}$, Angela Santoro ${ }^{7,8^{*}+}$ and Pantaleo Bufo ${ }^{1,9+}$
}

\begin{abstract}
The exact worldwide incidence of Burkitt's lymphoma is not known. There are three distinct clinical variants of Burkitt's lymphoma, each manifesting differences in epidemiology, clinical presentation, morphology, biology and genetic features: the endemic (African), the sporadic (non-endemic), and the immunodeficiency-associated form. In particular, we reported data regarding Burkitt's lymphoma incidence in the world and across different European countries. Finally, we described clinic-pathological data of 48 Burkitt's lymphomas occurred in Italy from 2003 to 2013, in 4 different hospitals, two of which located in east side, and the other ones located in the west-coast. Forty Burkitt's lymphomas occurs in children (age range 3-12), and 8 were adulthood Burkitt's lymphomas (age range 18-87). In the pediatric group the Male:Female ratio (M:F) was of 4:1, whereas the group of the adult patients has a M:F of 1:1.67. Immunohistochemical detection of Latent Membrane Protein 1 (LMP1) expression and Epstein-Barr virus Encoded RNA (EBER) In Situ Hybridization (ISH) procedures have been performed. Lymphocyte B monoclonal spread has been demonstrated using a Polymerase Chain Reaction (PCR) based method to amplify Fragment Restriction FR1, FR2 and FR3 immunoglobulin heavy chains DNA fragments. Only 38 cases out of 48 were analyzed for LMP-1 showing various percentage of stained cells in $47.4 \%$ of the patients.

Considering ISH for EBER detection results:

- 1 out 2 (50\%) adult analyzed cases was positive, with 50\% of stained tumor cells (this patient was a 22 years old female, coming from Napoli);

- 15 out 24 (62.5\%) children analyzed Burkitt's lymphomas resulted as positive for EBER;

- the overall positivity has been observed in 16/26 Burkitt's lymphomas (61.53\%).

- Finally, EBV has been detected in children and adult patients, one of them with deregulation of the oncogene c-MYC by chromosomal translocation.
\end{abstract}

Keywords: Burkitt's lymphoma, Immunohistochemistry, In situ hybridization

\section{Review of literature}

\section{EBV, Burkitt's Lymphoma and tumorigenesis}

Epstein Barr virus (EBV) or Human Herpesvirus 4 is an important example of a transforming virus belonging to the genus Lymphocryptoviridae, the gamma 1 subtype of the subfamily Gammaherpesviridae and is one of the

\footnotetext{
* Correspondence: angelasantoro1@hotmail.it

${ }^{\dagger}$ Equal contributors

${ }^{7}$ Department of Laboratory, Institute of Histopathology and Diagnostic Cytopathology, Fondazione di Ricerca e Cura 'Giovanni Paolo II'-UCSC, Campobasso, Italy

${ }^{8}$ Piazza Attilio Omodei Zorini, 48, int.6 00166, Rome, RM, Italy

Full list of author information is available at the end of the article
}

most common viruses in humans. It is able to infect more than $95 \%$ of all individuals within the first four decades of life.

EBV is usually acquired in early childhood in developing countries, with no specific characteristics other than the general symptoms of acute viraemia. However, in developed countries the infection is usually delayed until adolescence or early adulthood years where it is associated with the clinical syndrome referred as infectious mononucleosis. Following primary infection, EBV persists lifelong in the host, selectively infecting in a latent state memory B

\section{Biomed Central}


lymphocytes reservoir. The main viral genes involved in the transformation and persistence of infected $B$ cells are LMP1 and LMP2a. Through self-aggregation on the surface of the infected B cell, LMP1 and LMP2a provide active signals leading to the proliferation of transformed memory B cells that remain in the host for life [1]. LMP1 and other EBV proteins such as Epstein Barr Nuclear Antigen 2 (EBNA2), are highly antigenic, marking the infected B cells for destruction by cytotoxic T cells (CTLs) in the healthy individual. On the other hand, in immunodepressed patients as well as in transplant recipients undergoing immunosuppression, CTLs are immobilized, allowing for the proliferation and immortalization of infected B cells [1]. EBV has been demonstrated to be involved in the development of numerous malignancies, both in immunocompetent hosts and in immunocompromised individuals [2]. The first association was with the endemic Burkitt's lymphoma. The EBV genome is detected in the majority of neoplastic cells in all patients affected by endemic Burkitt's lymphoma $[3,4]$ and there is strong epidemiological association with endemic malaria [5], although there has never been a conclusive population study in support of a direct role of malaria in causation of Burkitt's lymphoma.

EBV may be detected also in approximately 30\% of sporadic Burkitt's lymphoma cases and it is identified in $25-40 \%$ of immunodeficiency-associated Burkitt's lymphomas [6].

A setting of profound immunosuppression, as in the terminal phases of Human Immunodeficiency Virus (HIV) infection or in organ transplant recipients, leads to loss of control of EBV infection, allowing deregulated proliferation of EBV infected lymphocytes. In this case a spectrum of EBV-driven lymph proliferation, ranging from hyperplasia to frank Non Hodgkin Lymphoma (NHL) could derive [7]. We have to remember that the majority of EBV infections that occur after transplantation, especially in adults, are clinically silent reactivations. This leads to a subsequent delay in the diagnosis of lymph proliferative disorders. Studies have shown a positive correlation between the level of EBV DNAemia after transplantation and the development of post-transplant lymph proliferative disorders (PTLD) which has significant implications in order to monitor and quantify EBV-DNA load after transplantation as a prognostic marker for the development of PTLD [8-10]. Other lymphomas (subtypes of both Hodgkin's and non-Hodgkin's lymphomas) are also known to be associated with EBV infection. Epithelial malignancies such as lymphoepitheliomas of nasopharynx [11] and gastric carcinoma [12] are currently included in the list of EBV associated tumours.

In a recent review, Thorley-Lawson et al. [13] described the relationship between EBV infection and Burkitt's lymphoma. The tumour cells were found to express EBNA in their nuclei, a serologically defined, putative tumour antigen, composed of six components, of which only one, EBNA-1, was expressed in EBV-positive Burkitt's lymphomas [14]. One observation that favored the carcinogenic role of EBV in Burkitt's lymphoma was the finding that EBV was an extremely potent transforming virus in culture for the same cell type that develops into Burkitt's lymphoma, the B lymphocyte [14], being able to convert $>50 \%$ of B cell into continuously proliferating, latently infected lymphoblastoid cell lines (LCLs) within a few days.

The link between EBV and human cancer is constantly evolving and it lies in the molecular events occurring in Burkitt's lymphoma pathogenesis.

EBV can display three patterns of latent gene expression: latency I (latency programme), II (default programme) and III (growth programme). Latency III is characterized by expression of all the latent genes (EBNAs, LMPs and EBERs) and occurs on primary infection of B cells. In contrast, persistent infection in vivo is characterized by expression of EBNA-1 and LMP-2 plus the EBERs [15]. In latently infected LCLs, EBV expresses the full spectrum of latent genes; two small nuclear RNAs (EBERs), the highly spliced BamHI rightward transcripts (BARTs), three integral latent membrane proteins, (LMP1, $-2 \mathrm{~A}$ and $-2 \mathrm{~B}$ ) and six EBV nuclear antigens (EBNA1, -2, -3A, -3B, $-3 \mathrm{C}$, and EBNA-LP) [16].

While EBNA-1 and the EBERs (latency I) have been generally thought to be the only EBV genes expressed in endemic Burkitt's lymphoma, with a specific role in prevention of apoptosis and survival of neoplastic cells, other recent studies have found that a minor proportion of these tumours has a novel form of latency with a different and broader gene expression profile than previously thought in which the EBNA-3A, 3B, 3C and LP latent genes are expressed in the absence of EBNA-2 and LMP-1 or 2 [17]. Subsequentely, further investigation has demonstrated that endemic Burkitt's lymphomas may be constituted of tumour cells expressing variable patterns of EBV gene expression, each of which confer a different level of resistance to apoptosis [17]. Thus, EBNA-1, 3A, 3B, 3C and LP positive and EBNA-2, LMP negative Burkitt's lymphoma cells were the most resistant to apoptosis, while EBNA-2 positive, LMP1negative Burkitt's lymphoma cells displayed reduced but "intermediate" resistance $[18,19]$.

Other studies suggested that biopsies performed on Burkitt's lymphomas mass can express additional latent proteins, including LMP1, LMP2A and EBNA2 [3]. In particular, LMP2A increases the levels of prosurvival $\mathrm{B}$ Cell Lymphoma (Bcl) family members in B lymphocytes, allowing for bypass of p53 inactivation in a MYC tumor model. Recently, some Authors have proposed a role for LMP2A early in development of Burkitt's lymphoma, 
where the survival signal allows for expansion of cells that contain a MYC translocation. The expanded cells increase the probability of acquiring a p53 mutation, leading to tumor progression. After the p53 mutation, the tumor cells become less dependent on LMP2A and immune selection may explain the low levels of LMP2A present in tumor biopsies [20].

\section{Burkitt's lymphoma}

Burkitt's lymphoma is a highly aggressive B cell NHL with an extremely short doubling time that often presents in extra nodal sites or as an acute leukemia. No single parameter (such as morphology, genetic analysis or immunophenotyping) can be used as the gold standard for the diagnosis of Burkitt's lymphoma, but a combination of several diagnostic techniques is necessary.

\section{Epidemiology}

The exact worldwide incidence of Burkitt's lymphoma is not known, as collection of these types of epidemiologic data is limited by a lack of resources that are needed for case ascertainment and accurate diagnosis in the developing countries that have the highest apparent incidence (eg, equatorial Africa) [21].

There are three distinct clinical variants of Burkitt's lymphoma, each manifesting differences in epidemiology, clinical presentation, morphology, biology and genetic features: the endemic (African), the sporadic (non-endemic), and the immunodeficiency-associated form. The endemic and sporadic clinical variants of Burkitt's lymphoma differ geographically.

a. Endemic Burkitt's lymphoma occurring in Equatorial Africa, Papua New Guinea, represents the most common childhood malignancy of these areas, and shows geographic occurrence corresponding to the geographical distribution of endemic malaria [22]. Burkitt's lymphoma accounts for 30 to 50 percent of all childhood cancer in equatorial Africa with an estimated incidence of 3 to 6 cases per 100,000 children per year [21]. The peak incidence occurs in children age four to seven years, and the male:female ratio is approximately $2: 1$.

b. Sporadic Burkitt's lymphoma occurring in the US and Western Europe children and young adults. This variant accounts for $30-50 \%$ of all childhood lymphomas and less than 1 percent of adult NHLs in the US [23], with an estimated incidence of approximately three cases per million persons per year in both children and adults. In Europe, the incidence is approximately 2.2 cases per million persons per year [24]. The peak incidence occurs in children age 11 years. Among adults, sporadic Burkitt's lymphoma is typically seen in patients less than 35 years of age, with a median age at diagnosis of 30 years [25]. The majority of patients are males with a 3 or 4:1 male:female ratio $[22,26,27]$.

\section{c. Immunodeficiency-associated Burkitt's}

lymphoma occurring in association with the HIV infection, and less commonly in patients with other causes of immunodeficiency (e.g., recipients of organ transplants). In HIV + patients, Burkitt's lymphoma typically occurs as the initial manifestation of the acquired immunodeficiency syndrome and affects those still immune competent patients with a relatively high CD4 count (e.g., >200 cells/microL) and no opportunistic infections [28], in this way suggesting that HIV itself may have an oncogenic role [29]. In comparison to the majority of other HIV-associated lymphomas, the rate of Burkitt's lymphoma in the HIV-positive population has not decreased with the advent of Highly Active Anti-viral Therapy (HAART).

The geographic distribution of Burkitt's lymphoma identifies high, intermediate and low-risk areas [30]. The area of highest risk for Burkitt's lymphoma appears to be between $10^{\circ}$ north and $10^{\circ}$ south of the equator and in Papua New Guinea. The zone of intermediate risk for Burkitt's lymphoma encompasses Southern Europe (Spain, France and Portugal), North Africa, and Asia as far west as Iraq and Kuwait Countries in this zone include also Denmark and the Netherlands since both have slightly elevated Age Standardized Rates compared with the general pattern in Northern and Eastern Europe. The zone of low risk includes most of the remainder of Northern and Eastern Europe, and North and parts of South America and East Asia. In these areas Burkitt's lymphoma accounts for $6-15 \%$ of lymphomas.

\section{Etiology}

Burkitt's lymphoma was first described in 1958 by a British surgeon working in Uganda who noted a unique, rapidly growing jaw malignancy in children, that was especially common in low altitude, high rainfall areas with a mean temperature over 16 Celsius degrees [31]. The distribution corresponded with that of holoendemic malaria [32], implicating malaria in the aetiology. In 1964, the EBV was identified in cultured cell-lines of the tumour [33], and its consistent presence in African Burkitt's lymphoma implicated a virus in the aetiology of a human cancer for the first time [34]. The EBV is found in up to 95\% of Burkitt's lymphoma tumours from high-risk areas [35], but in fewer than 30\% from low-risk countries [36]. Areas of intermediate risk have intermediate proportions of EBV positive $(\mathrm{EBV}+)$ tumours [37]. However, recent works suggest that a low socio-economic status and an early EBV 
infection can be associated with a higher prevalence of $\mathrm{EBV}+$ Burkitt's lymphoma in low-incidence areas. In immunodeficiency-associated cases EBV is identified in only $25-40 \%$ of the cases. However epidemiological studies suggest that malaria and EBV or HIV alone cannot account for the distribution of endemic Burkitt's lymphoma in high risk countries. Clustering in time and space, and within same families has been observed, particularly in areas of high incidence, but so far these studies have failed to firmly implicate either genetic or environmental factors. Finally, arboviruses and plant tumour promoters are other possible local cofactors.

\section{Genetics}

Different and multiple environmental exposure may converge in a common pathogenetic mechanism involving the MYC gene at chromosome 8q24. In fact, all tumours contain the same chromosomal translocations, which culminate in the deregulation of the oncogene c-MYC. The translocations involve the $M Y C$ location (8q24) and one of the immunoglobulin loci on chromosomes 2, 14, or 22 [38,39]. Most of the cases of Burkitt's lymphomas presented the $M Y C$ translocation at band $8 \mathrm{q} 24$ to the Immunoglobuline heavy chain locus (IGH) (14q32) or, less commonly, at the lambda (22q11) or kappa (2p12) light chain loci (IGL). The reciprocal translocation $\mathrm{t}(8: 14)$ occurs in approximately $80 \%$ of tumours [40], the remaining $20 \%$ being represented by $t(2 ; 8)$ and $t(8 ; 22)$. In African endemic cases, the breakpoint on chromosome 14 involves the heavy-chain joining region and originate from aberrant somatic hypermutation, whereas in sporadic forms, the translocation involves the heavy chain switch region [41]. Finally, up to $10 \%$ of the cases may lack a demonstrable $M Y C$ translocation by Fluorescence In Situ Hybridation (FISH), otherwise evidenced using other molecular techniques. Translocation and deregulation involving $M Y C$ gene on chromosome 8 is highly characteristic but not specific for Burkitt's lymphoma. Other genetic and epigenetic alterations can occur in a subgroup of Burkitt's lymphoma, involving for example TP53 in immune-competent and immunedeficient patients, HIV positive individuals and transplants recipients [42]. In a recent work the first completely sequenced genome from a Burkitt's lymphoma tumor and germ line DNA from the same affected individual has been described [43]. Authors further sequenced the exomes of 59 Burkitt's lymphoma tumors, comparing them to sequenced exomes from 94 Diffuse Large B Cell Lymphomas (DLBCLs). 70 genes that were recurrently mutated in Burkitt's lymphomas, including Inhibitor of DNA binding 3 (ID3), Guanine Nucleotide-binding Protein Alpha 13 (GNA13), Rearranged during Transfection oncogene (RET), Phosphatidyl Inositol 3-Kinase Regulatory Subunit 1 (Pi3KR1) and the Switch/Sucrose
Non Fermentable (SWI/SNF) genes, AT Rich Interactive Domain 1A (ARID1A) and SWI/SNF-related MatrixAssociated Actin-Depended Regulator of Chromatin subfamily A-member 4 (SMARCA4) have been identified. In particular ID3 mutations occurred in 34\% of Burkitt's lymphomas and not in DLBCLs.

\section{Histopathology}

Despite chromosomal differences, the "endemic" and "sporadic" forms are indistinguishable morphologically and cytologically [44]. The classical prototype of Burkitt's lymphoma is observed in endemic form and in a high percentage of sporadic cases, particularly in children, but in only a minority of sporadic and immunodeficiency associated adult cases. Neoplastic cells are uniform and small-medium sized with round nuclei, similar or smaller to those of histiocytes, and several or multiple small basophilic paracentrally situated nucleoli. Cytoplasm is deeply basophilic, moderately abundant; it can show slight retraction after formalin fixation and contains lipid vacuoles. Neoplastic cells show a diffuse monotonous pattern of growth, a high mitotic count as well as high apoptotic fraction. Characteristically, there are numerous admixed tingible body macrophages, phagocytosing abundant apoptotic debris and creating a starry-sky pattern. Some cases, characterized by a limited stage disease and a good prognosis, may also have a florid granulomatous reaction, causing diagnostic problems in the recognition of the tumour. There are cases in which tumor cells exhibit eccentric nucleus with a single central nucleolus: these cases are referred as Burkitt's lymphoma with plasmacytoid differentiation and can be observed more commonly in immunodeficient patient. Other cases, in the past defined as atypical Burkitt's lymphoma/Burkitt like lymphoma, may show greater nuclear pleomorphism with more prominent nucleoli, but fewer in number. Atypical Burkitt's lymphomas occur more frequently in many cases of sporadic adult forms.

\section{Immunophenotype}

Burkitt's lymphoma, regardless of subtype typically expresses monotypic surface IgM with light chain restriction, pan-B-cell antigens, including the CD19, CD20, CD22 and CD79a and co-expresses CD10, CD38, CD43, CD77, Bcl6, and p53, but not CD5, CD23, Bcl2 (or only weakly positive in almost $20 \%$ of cases, generally adult patients), CD138 or TdT, thus suggesting follicle centre origin. Burkitt's lymphoma with plasmacytoid differentiation has in addition monotypic cytoplasmic Ig. The proliferation index is near to $100 \%$.

\section{Clinical features and prognosis}

Staging is performed using the Ann Arbor or, more often, the St Jude/Murphy staging system [45]. Approximately 
$30 \%$ of patients present with limited-stage disease (I or II), while $70 \%$ present with widespread disease (stage III or IV). Patients often present with bulky disease, a high tumour burden due to its short doubling time, and with a high risk for spread to the central nervous system (CNS) and bone marrow. A minority of patients with Burkitt's lymphoma presents with leukemic disease, previously classified as ALL (acute lymphocytic leukaemia), L3 type. In endemic Burkitt's lymphomas, the jaws and other facial bones are the most frequent sites of clinical presentation. The distal ileum, coecum, omentum, gonads, kidneys, long bones, thyroid, salivary glands and breast may also be affected. In sporadic Burkitt's lymphomas, jaw tumours are rare, while the majority of case are represented by intra-abdominal masses. In immunodeficiency associated forms, nodal localization is frequent as well as bone marrow involvement. Sporadic and immunodeficiencyassociated Burkitt's lymphomas do not share endemic Burkitt's lymphomas exquisite sensitivity to chemotherapy, therefore historically the prognosis had been poor, particularly among adults. Although the most important prognostic features have yet to be determined, some clinical factors associated with worse outcome in adults and children include older age, advanced stage, poor performance status, bulky disease, high Lactate Dehydrogenase (LDH), and CNS or marrow involvement, unresectable tumour $>10 \mathrm{~cm}$ in diameter. Among paediatric patients, a poorer prognosis is associated with age over 15 years [46]. A good prognosis is associated with resectable abdominal disease [44]. High-intensity chemotherapy, sometimes combined with CNS prophylaxis, yields excellent survival in children, both with localized disease and with widespread disease [47]. When similar aggressive chemotherapeutic regimens have been administered to adults, good outcomes have been achieved, with overall survival (OS) rates of $50 \%-70 \%$ [48].

\section{WHO 2008 Classification: a new entity}

The WHO provides an overlap category termed "B cell lymphoma, unclassifiable, with features intermediate between diffuse large B cell lymphoma and Burkitt lymphoma".

These neoplasms are very aggressive lymphomas that share morphological and genetic features of DLBCL and Burkitt's lymphoma, but for biological and clinical reasons should be not included in one of the two categories. Morphologically these lymphomas are typically composed of a diffuse proliferation of medium-large sized cells with few admixed small lymphocytes and no stromal fibrosis. A starry-sky pattern, as well as many mitotic figures and apoptotic bodies can be observed, resembling Burkitt's lymphoma.

There is a marked cellular pleomorphism: in some cases, cells resemble those of Burkitt's lymphoma but with more variation in nuclear size and cellular contour; other cases are morphologically similar to Burkitt's lymphoma, but with an atypical immunophenotype or genetic features; other cases share the same immunophenotype of Burkitt's lymphoma but have an intermediate morphology between Burkitt's lymphoma an DLBCL; in rare cases, defined 'blastic or blastoid', the nuclei are very small, resembling lymphoblastic lymphoma.

The diagnosis of this unclassifiable type of lymphomas should not be made in:

- cases of morphologically typical DLBCL with $M Y C$ rearrangement;

- typical Burkitt's lymphomas in which a $M Y C$ rearrangement cannot be demonstrated;

- atypical Burkitt's lymphomas with a demonstrable IG-MYC rearrangement.

Cases that morphologically resemble Burkitt's lymphoma and or DLBCL may be placed in this category when:

- the immunophenotype is suggestive of Burkitt's lymphoma (CD10+, Bcl6+, Bcl2-);

- $\mathrm{Bcl} 2$ is moderately-strongly positive (double-hit lymphoma with bot $M Y C$ an BCL2 translocations);

- Ki67 labelling expression is heterogeneous (50-100\%);

- TdT is positive

These intermediate lymphomas express B-cell markers and surface Ig, that in so called double-hit cases can stain negative.

Approximately $35-50 \%$ of the cases have $8 \mathrm{q} 24 / M Y C$ translocations. Many cases have non IG-MYC translocations, approximately $15 \%$ having a BCL2 translocation, sometimes also together $M Y C$ translocations (double-hit lymphomas). Less frequently, BCL6 translocation have been observed together $M Y C$ and/or BCL2. These type of double/triple hit lymphomas reflect a complex karyotype and are more common in elderly patients [25].

\section{Differential diagnosis}

The main diagnostic problem is to differentiate Burkitt's lymphoma from other types of high-grade B-cell lymphoma, especially from diffuse large B-cell lymphoma. This problem is most evident for adults because a much lower proportion of NHLs in adults is Burkitt's lymphoma if compared with children population, and because adults (more than children) often have the atypical Burkitt's lymphoma variant, with morphologic features resembling those of diffuse large B-cell lymphoma.

The immunophenotypic prototype of Burkitt's lymphoma is IgM+/CD10+/bcl-2-/bcl-6+ with the Ki-67 proliferation index (PI) nearly at $100 \%$; however, cases with an aberrant immunophenotype (such as bcl-2 expression) exist [49]. Occasional diffuse large B-cell lymphomas may 
exhibit a very high PI, have medium-sized tumor cells showing slight nuclear pleomorphism, with or without a starry-sky pattern (DLBCL-HPSS). Furthermore, some DLBCLs may share immunophenotypic features of Burkitt's lymphoma [50]. Furthermore, $c-M Y C$ rearrangement is not unique in Burkitt's lymphoma and may occur in DLBCLs [49]. These gray-zone cases is an important diagnostic challenge, because the distinction is of great clinical significance for the different treatment strategies for Burkitt's lymphoma and DLBCL [45]. Generally, we can consider the following key-points to make a correct differential diagnosis.

Features that favour Burkitt's lymphoma include morphology, an immunophenotype that is CD20+, CD10+, Bcl-6+, Bcl-2-, TdT-, and monotypic sIg+, with virtually all cells $\mathrm{Ki67+}$ (proliferation), and a translocation involving c-Myc and $\mathrm{IgH}$ or IgL, without rearrangements involving the bcl2 or bcl-6 genes [49]. Features that rule out the diagnosis of Burkitt's lymphoma include BCL6 gene rearrangement, independent from bcl-6 nuclear staining, bcl-2 positivity, presence of $\mathrm{t}(14 ; 18)$ and a ki67 staining less than $95 \%$. $c-M Y C$ protein expression has been suggested to favour Burkitt's lymphoma over DLBCL, but rare cases of Burkitt's lymphoma can be $\mathrm{c}-M Y C$ protein negative and some large B-cell lymphomas also express $c-M Y C$ protein $(5 \%-15 \%$ of them having a $M Y C$ rearrangement) [51].

Studies of micro RNA (miRNA) profiling have evidenced the molecular differences existing between Burkitt's lymphoma and DLBCL and have demonstrated that the three Burkitt's lymphoma variants are representatives of the same biological entity with only marginal miRNA expression differences between endemic and sporadic form [52]. In particular, a signature of 38 miRNAs containing $M Y C$ and nuclear factor- $\mathrm{kB}(\mathrm{NF}-\mathrm{kB})$ pathway-associated miRNAs has been obtained, differentiating Burkitt's lymphoma from DLBCL.

Other type of lymphoproliferative diseases (follicular lymphoma, mantle-cell lymphoma, and plasma-cell myeloma) infrequently share $M Y C$ translocations. In lymphomas other than Burkitt type, c-myc is more likely to have variant translocations (with $\operatorname{IgL}$ or other non-Ig partners, rather than $\operatorname{IgH}$ ), and neoplastic cells tend to have more complex karyotypic abnormalities.

Other entities taking part in the differential diagnosis of Burkitt's lymphoma include $\mathrm{T}$ lymphoblastic lymphoma/ leukemia (expressing $\mathrm{T}$ cell markers and $\mathrm{TdT}$ ) and blastoid mantle cell lymphoma (CD5 and cyclin D1 positive).

The florid follicular hyperplasia, with highly active follicle centers with many blast cells and tingible body macrophages, overlaps with the starry-sky appearance and with the immunophenotype of Burkitt's lymphoma. Demonstration of monotypic surface immunoglobulin can definitively exclude a reactive process.

\section{Clinic-pathological data of Burkitt's lymphoma cases occurred in Italy from 2003 to 2013. A representative four hospitals based survey \\ Patient cohort characteristics}

Upon approval by the Ethical Committees of the participants institutions, anatomic pathologists and physicians from four Italian hospitals were asked to furnish data regarding Burkitt's lymphomas occurred in Italy in the last ten years (2003-20013). Two hospitals were located in east Italy: University Hospital of Foggia and General Hospital of Ascoli Piceno. The other hospitals are located in the west-coast of Italy: General Hospital - AORN Ospedale dei Colli 'Vincenzo Monaldi', Napoli) and Children University Hospital - Ospedale Santobono Pausillipon, Napoli. A total of 48 cases of Burkitt's lymphomas has been recorded. Patients came from Foggia, Napoli and Ascoli Piceno and their broad provinces.

The study population consisted of 40 children and 8 adults. In children group there were 32 boys and 8 girls with a male to female ratio of $4: 1$; in the adult population there were 3 males and 5 females with a M:F of $1: 1,65$. Concerning the primary clinical presentation, our Burkitt's lymphomas of the adults occur as a node mass in 3 cases and as abdominal mass as well as iliac and appendiceal mass in one case respectively. Abdominal mass is the most common manifestation of Burkitt's lymphoma of the child in our study, this presentation occurring overall in 12 patients (30\%). In eight children $(20 \%)$ it arises as superficial nodes mass in 4 cases $(10 \%$ of all lymphomas) involving cervical nodes, in 2 as inguinal nodes mass and in 2 as axillary node mass (coinciding with $5 \%$ of all lymphomas). In 2 patients the disease arises with tonsils involvement and in other 2 cases with pleural effusion. Furthermore, the primary presentation with liver, retroperitoneum, mesocolon nodes, small bowel involvement and as a pelvic or mesenteric mass regards individuals patients (each case represents the 2,5\% of all lymphomas). Staging is performed using the St Jude/Murphy staging system [45]. All patients and/or their relatives gave their informed written consent.

\section{Materials and methods}

The specimens from all cases were fixed in $10 \%$ formalin, processed by routine methods, and embedded in paraffin. The final diagnosis of Burkitt's lymphoma, obtained comparing morphological features with immunohistochemical results for a panel of antibodies including CD3, CD5, CD20, CD10, CD79a, bcl-2, bcl-6 and Ki-67 (MIB-1), was carefully reviewed at the Section of Pathology of the University of Foggia by two pathologists (GP and RZ) and showed in Table 1.

Immunohistochemical detection of LMP1 Expression and EBER In Situ Hybridization Procedures have been 
Table 1 Clinico-pathological features of Italian study population and results regarding immunohistochemical findings

\begin{tabular}{|c|c|c|c|c|c|c|c|c|c|c|c|c|c|c|}
\hline \multirow[t]{2}{*}{ Case } & \multirow[t]{2}{*}{ Italian City (Region) } & \multirow[t]{2}{*}{ Year } & \multirow[t]{2}{*}{ Age } & \multirow[t]{2}{*}{ Sex } & \multirow[t]{2}{*}{ Site } & \multicolumn{9}{|c|}{ Immunohistochemistry (IHC) } \\
\hline & & & & & & CD20 & CD79a & CD10 & CD3 & CD5 & $\mathrm{Bcl}-6$ & $\mathrm{Bcl}-2$ & Ki67 & LMP1 \\
\hline Case 1 & Foggia (Puglia) & 2012 & 8 & M & Tonsil & $P$ & $P$ & $P$ & $\mathrm{~N}$ & n.d. & $P$ & $\mathrm{~N}$ & $>90$ & $\mathrm{~N}$ \\
\hline Case 2 & Foggia (Puglia) & 2012 & 52 & $\mathrm{~F}$ & Node & $P$ & $P$ & $P$ & $\mathrm{~N}$ & $\mathrm{~N}$ & $P$ & $\mathrm{~N}$ & $>95$ & N \\
\hline Case 3 & Foggia (Puglia) & 2006 & 38 & M & Abdominal mass & $P$ & $P$ & n.d. & $\mathrm{N}$ & n.d. & n.d. & n.d. & n.d. & n.d. \\
\hline Case 4 & Ascoli Piceno (Marche) & 2005 & 41 & $\mathrm{~F}$ & Node & $P$ & n.d. & N & N & n.d. & $P$ & $\mathrm{~N}$ & 100 & N \\
\hline Case 5 & Ascoli Piceno (Marche) & 2006 & 18 & $\mathrm{~F}$ & Node & $\mathrm{P}$ & n.d. & $P$ & $\mathrm{~N}$ & n.d. & $P$ & $P$ & 100 & $\mathrm{~N}$ \\
\hline Case 6 & Ascoli Piceno (Marche) & 2011 & 87 & M & Ileum & $P$ & n.d. & N & $\mathrm{N}$ & n.d. & $P$ & n.d. & 98 & $P$ \\
\hline Case 7 & Ascoli Piceno (Marche) & 2012 & 37 & M & Appendix & $P$ & $P$ & n.d. & $\mathrm{N}$ & n.d. & $P$ & $\mathrm{~N}$ & 100 & n.d. \\
\hline Case 8 & Naples* (Campania) & 2003 & CHILD & M & Retroperitoneum & $P$ & $P$ & n.d. & $\mathrm{N}$ & n.d. & n.d. & n.d. & $>95$ & $P$ \\
\hline Case 9 & Naples* (Campania) & 2003 & CHILD & M & Abdominal mass & $P$ & $P$ & n.d. & $\mathrm{N}$ & n.d. & n.d. & n.d & $>95$ & $P$ \\
\hline Case 10 & Naples* (Campania) & 2003 & CHILD & M & Small bowel & $P$ & $P$ & n.d. & $\mathrm{N}$ & n.d. & n.d. & n.d. & $>95$ & $P$ \\
\hline Case 11 & Naples* (Campania) & 2003 & CHILD & M & Ileum & $\mathrm{P}$ & $P$ & n.d. & $\mathrm{N}$ & n.d. & n.d. & n.d. & $>95$ & n.d. \\
\hline Case 12 & Naples* (Campania) & 2003 & CHILD & $\mathrm{F}$ & Mesocolon nodes & $P$ & n.d. & n.d. & $\mathrm{N}$ & n.d. & n.d. & $\mathrm{N}$ & $>95$ & $P$ \\
\hline Case 13 & Naples* (Campania) & 2004 & 4 & M & Abdominal mass & $P$ & $P$ & $P$ & N & n.d & $P$ & $\mathrm{~N}$ & $>90$ & $P$ \\
\hline Case 14 & Naples* (Campania) & 2004 & 5 & M & Cervical nodes. & $\mathrm{P}$ & $P$ & $P$ & $\mathrm{~N}$ & n.d & n.d & n.d & $>95$ & n.d. \\
\hline Case 15 & Naples* (Campania) & 2004 & CHILD & M & Axillary nodes & $P$ & $P$ & n.d & $\mathrm{N}$ & n.d & n.d & n.d & $>95$ & n.d. \\
\hline Case 16 & Naples* (Campania) & 2004 & CHILD & $\mathrm{F}$ & Nasopharinx & $P$ & $P$ & n.d & $\mathrm{N}$ & n.d & n.d & n.d & $>95$ & $P$ \\
\hline Case 17 & Naples* (Campania) & 2005 & 6 & M & Abdominal mass & $P$ & $P$ & $P$ & $\mathrm{~N}$ & n.d & $P$ & $\mathrm{~N}$ & $>95$ & $P$ \\
\hline Case 18 & Naples* (Campania) & 2005 & 6 & M & Inguinal nodes & $P$ & $P$ & $P$ & $\mathrm{~N}$ & n.d & $P$ & $\mathrm{~N}$ & $>95$ & n.d. \\
\hline Case 19 & Naples* (Campania) & 2005 & 4 & $\mathrm{~F}$ & Pelvic mass & $P$ & $P$ & $P$ & $N$ & n.d & $P$ & $\mathrm{~N}$ & $>95$ & $P$ \\
\hline Case 20 & Naples* (Campania) & 2005 & 3 & $\mathrm{~F}$ & Ileum & $P$ & $\mathrm{P}$ & $\mathrm{P}$ & N & n.d & $P$ & $\mathrm{~N}$ & $>95$ & $\mathrm{~N}$ \\
\hline Case 21 & Naples* (Campania) & 2005 & 11 & M & Axillay nodes & $P$ & $P$ & $P$ & N & n.d & $P$ & $\mathrm{~N}$ & 100 & $\mathrm{~N}$ \\
\hline Case 22 & Naples* (Campania) & 2005 & 4 & $\mathrm{~F}$ & Ileum & $P$ & $P$ & $P$ & N & n.d & $P$ & $\mathrm{~N}$ & 90 & $P$ \\
\hline Case 23 & Naples* (Campania) & 2005 & 12 & M & Abdominal mass & $P$ & $P$ & $P$ & $\mathrm{~N}$ & n.d & $P$ & $\mathrm{~N}$ & $>95$ & $\mathrm{~N}$ \\
\hline Case 24 & Naples* (Campania) & 2006 & 5 & M & Inguinal nodes & $P$ & $P$ & $P$ & $\mathrm{~N}$ & n.d & $P$ & $\mathrm{~N}$ & 100 & $P$ \\
\hline Case 25 & Naples* (Campania) & 2006 & 8 & M & Abdominal mass & $P$ & n.d & $P$ & $\mathrm{~N}$ & n.d & $P$ & $\mathrm{~N}$ & $>90$ & $P$ \\
\hline Case 26 & Naples* (Campania) & 2006 & 12 & $\mathrm{~F}$ & Ileum & $P$ & $P$ & $P$ & $\mathrm{~N}$ & n.d & $P$ & Focal P & 90 & $\mathrm{~N}$ \\
\hline Case 27 & Naples* (Campania) & 2006 & 7 & M & Mesenteric mass & $P$ & $P$ & $P$ & N & n.d & $P$ & $\mathrm{~N}$ & $>95$ & $P$ \\
\hline Case 28 & Naples* (Campania) & 2006 & 8 & M & Liver & $P$ & n.d & $P$ & $N$ & n.d & $P$ & $\mathrm{~N}$ & 100 & $P$ \\
\hline Case 29 & Naples* (Campania) & 2007 & 6 & $\mathrm{~F}$ & Abdominal mass & $P$ & n.d & n.d & $\mathrm{N}$ & n.d & n.d & $\mathrm{N}$ & 100 & n.d. \\
\hline Case 30 & Naples* (Campania) & 2007 & 7 & M & nasopharynx & $P$ & n.d & $P$ & N & n.d. & $P$ & $\mathrm{~N}$ & $>95$ & N \\
\hline Case 31 & Naples* (Campania) & 2007 & 7 & M & Tonsil & $\mathrm{P}$ & n.d & $P$ & $\mathrm{~N}$ & n.d. & $P$ & $\mathrm{~N}$ & $>95$ & n.d. \\
\hline Case 32 & Naples* (Campania) & 2007 & 4 & M & Abdominal mass & $P$ & $P$ & $P$ & $\mathrm{~N}$ & n.d. & $P$ & $\mathrm{~N}$ & 95 & $P$ \\
\hline Case 33 & Naples* (Campania) & 2007 & 6 & M & Cervical nodes & $P$ & $\mathrm{P}$ & $\mathrm{P}$ & $\mathrm{N}$ & n.d. & $P$ & $\mathrm{~N}$ & 95 & $\mathrm{~N}$ \\
\hline Case 34 & Naples* (Campania) & 2008 & 10 & M & Abdominal mass & $P$ & $P$ & $P$ & $\mathrm{~N}$ & n.d. & $P$ & $\mathrm{~N}$ & $>90$ & $P$ \\
\hline Case 35 & Naples* (Campania) & 2008 & 7 & M & Nasopharynx & $P$ & $P$ & $P$ & $\mathrm{~N}$ & n.d. & $P$ & $\mathrm{~N}$ & 100 & $\mathrm{~N}$ \\
\hline Case 36 & Naples* (Campania) & 2008 & 6 & M & Cervical nodes & $P$ & $P$ & $P$ & $\mathrm{~N}$ & n.d. & $P$ & $\mathrm{~N}$ & $>95$ & $P$ \\
\hline Case 37 & Naples* (Campania) & 2008 & 11 & M & Cervical nodes & $\mathrm{P}$ & $P$ & $P$ & $\mathrm{~N}$ & n.d. & $P$ & $\mathrm{~N}$ & 100 & $\mathrm{~N}$ \\
\hline Case 38 & Naples* (Campania) & 2008 & 10 & M & Abdominal mass & $P$ & $P$ & $P$ & $\mathrm{~N}$ & $\mathrm{~N}$ & $P$ & $\mathrm{~N}$ & $>95$ & $\mathrm{~N}$ \\
\hline Case 39 & Naples* (Campania) & 2009 & 3 & M & Abdominal mass & $P$ & $P$ & $P$ & $\mathrm{~N}$ & N & $P$ & $\mathrm{~N}$ & $>90$ & N \\
\hline Case 40 & Naples* (Campania) & 2010 & 11 & M & Abdominal mass & $P$ & $P$ & $\mathrm{P}$ & $\mathrm{N}$ & N & $P$ & $\mathrm{~N}$ & $>95$ & $\mathrm{~N}$ \\
\hline Case 41 & Naples* (Campania) & 2010 & 11 & M & Abdominal mass & $P$ & $P$ & $P$ & $\mathrm{~N}$ & n.d. & $P$ & $\mathrm{~N}$ & 100 & $\mathrm{~N}$ \\
\hline Case 42 & Naples* (Campania) & 2010 & 5 & $\mathrm{~F}$ & Nasopharynx & $P$ & n.d. & $P$ & $\mathrm{~N}$ & n.d. & $P$ & $\mathrm{~N}$ & 100 & $\mathrm{~N}$ \\
\hline Case 43 & Naples* (Campania) & 2011 & 6 & M & Ileum & P & $P$ & $\mathrm{P}$ & $\mathrm{N}$ & N & P & $\mathrm{N}$ & 95 & P \\
\hline
\end{tabular}


Table 1 Clinico-pathological features of Italian study population and results regarding immunohistochemical findings (Continued)

\begin{tabular}{|c|c|c|c|c|c|c|c|c|c|c|c|c|c|c|}
\hline Case 44 & Naples* (Campania) & 2012 & 9 & M & Ileum & $P$ & $P$ & $P$ & $\mathrm{~N}$ & $\mathrm{~N}$ & $P$ & $\mathrm{~N}$ & $>90$ & $\mathrm{~N}$ \\
\hline Case 45 & Naples* (Campania) & 2012 & 6 & M & Pleural effusion & $P$ & $P$ & $P$ & $\mathrm{~N}$ & n.d. & $P$ faint & $\mathrm{N}$ & $>90$ & $\mathrm{~N}$ \\
\hline Case 46 & Naples* (Campania) & 2013 & 3 & M & Pleural effusion & $P$ & $P$ & $P$ & $\mathrm{~N}$ & n.d. & $P$ & $\mathrm{~N}$ & 100 & $\mathrm{~N}$ \\
\hline Case 47 & Naples (Campania) & 2003 & 67 & $\mathrm{~F}$ & n.d. & $P$ & $P$ & n.d. & $\mathrm{N}$ & n.d. & n.d. & n.d. & n.d. & n.d. \\
\hline Case 48 & Naples (Campania) & 2003 & 22 & $\mathrm{~F}$ & n.d. & $P$ & $P$ & $P$ & $\mathrm{~N}$ & $\mathrm{~N}$ & n.d. & n.d. & n.d. & n.d. \\
\hline
\end{tabular}

Legend. *, Ospedale Santobono Pausillipon; ${ }^{\circ}$, AORN Ospedale dei Colli -'Vincenzo Monaldi'; P, positive; N, negative; n.d., not determined.

performed and evaluated according to standardized guidelines [53].

In our study In Situ Hybridization (ISH) has been performed using Ventana EBER ISH iView Blue Plus Kit. It is performed using a cocktail of EBV encoded small RNA probes. The intended target is the early RNA transcripts of EBV accumulated in the nucleus of EBV-infected cells as evaluated by a blue reaction that is localized to EBV-infected nuclei.

In our study, Lymphocyte B monoclonal spread has been demonstrated using a PCR based method to amplify FR1, FR2, and FR3 immunoglobulins heavy chains DNA fragments according to manufacturer instructions (Invitrogen, Carlsbad, CA, USA).

At first time the slides were assessed either positive or negative for EBV latent infection. The cases assessed as positive were then examined as regard the percentage value of stained cells.

\section{Results and discussion}

After active infection the EBV resides in a latent form with $B$ cells providing the main cellular reservoir [54]. Latent infection by EBV can occur in three forms (latency I, latency II and latency III), each one being marked by a different viral gene expression profile. In fact, not all stages of EBV latency express LMP-1 and questions have been raised about the sensitivity of the immunohistochemistry (IHC) to detect the virus.

Detection of EBV can be also performed by EBER insitu hybridization (ISH). EBER actually consists of two small EBV latency transcripts of 166 and 172 bases respectively, called EBER-1 and EBER-2 [55]. These transcripts are non-polyadenlylated and therefore not translated into proteins, detectable by IHC. They are naturally amplified and present at high levels in all latency forms of EBV infection, making them ideal targets for ISH, which is widely considered the gold standard for the detection of EBV latent infection in formalin fixed, paraffin embedded tissue (FFPE), being more sensitive than the immunohistochemical evaluation of LMP-1 expression [56].

In our study EBV has been detected both in adult patients (in one of them with deregulation of the oncogene
c-MYC by chromosomal translocation) and children by two different diagnostic tests. Histopathologic, immunohistochemical and ISH findings, useful to achieve the final diagnosis of Burkitt's lymphoma have been reported in Table 1 and showed in Figures 1, 2, 3 and 4.

The immunohistochemical detection of LMP-1 was analyzed in 38 samples (Figure 3).

In the adult population the detection was performed in 4 cases and just 1 expressed LMP-1 (25\%). We have information about the presence of deregulation of the oncogene c-MYC by its chromosomal translocation at band $8 \mathrm{q} 24$ to the Ig heavy chain region $\operatorname{IgH}(14 q 32)$ in two lymphomas; one of them was precisely the adult Burkitt's lymphoma positive for LMP-1 (in almost 25\% of neoplastic cell). In particular, this case referred to a male patient, 37 years old, living in Ascoli Piceno. He is the only patient without Italian origins, as he comes from the Republic of Peru.

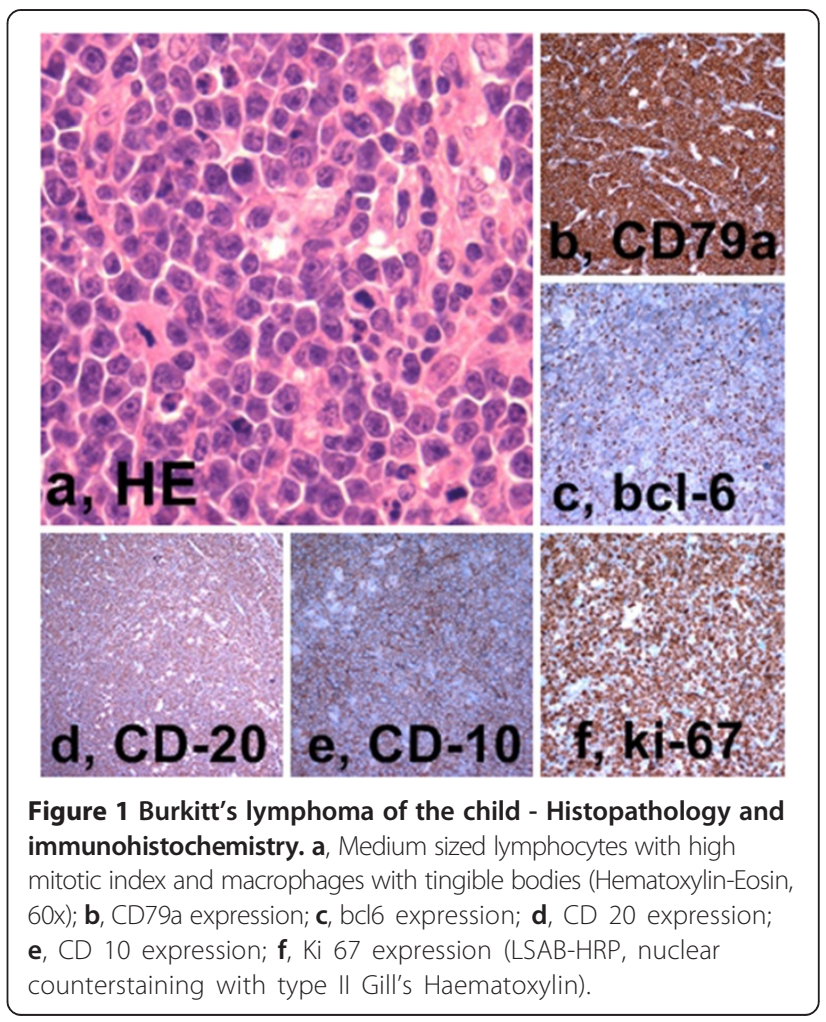




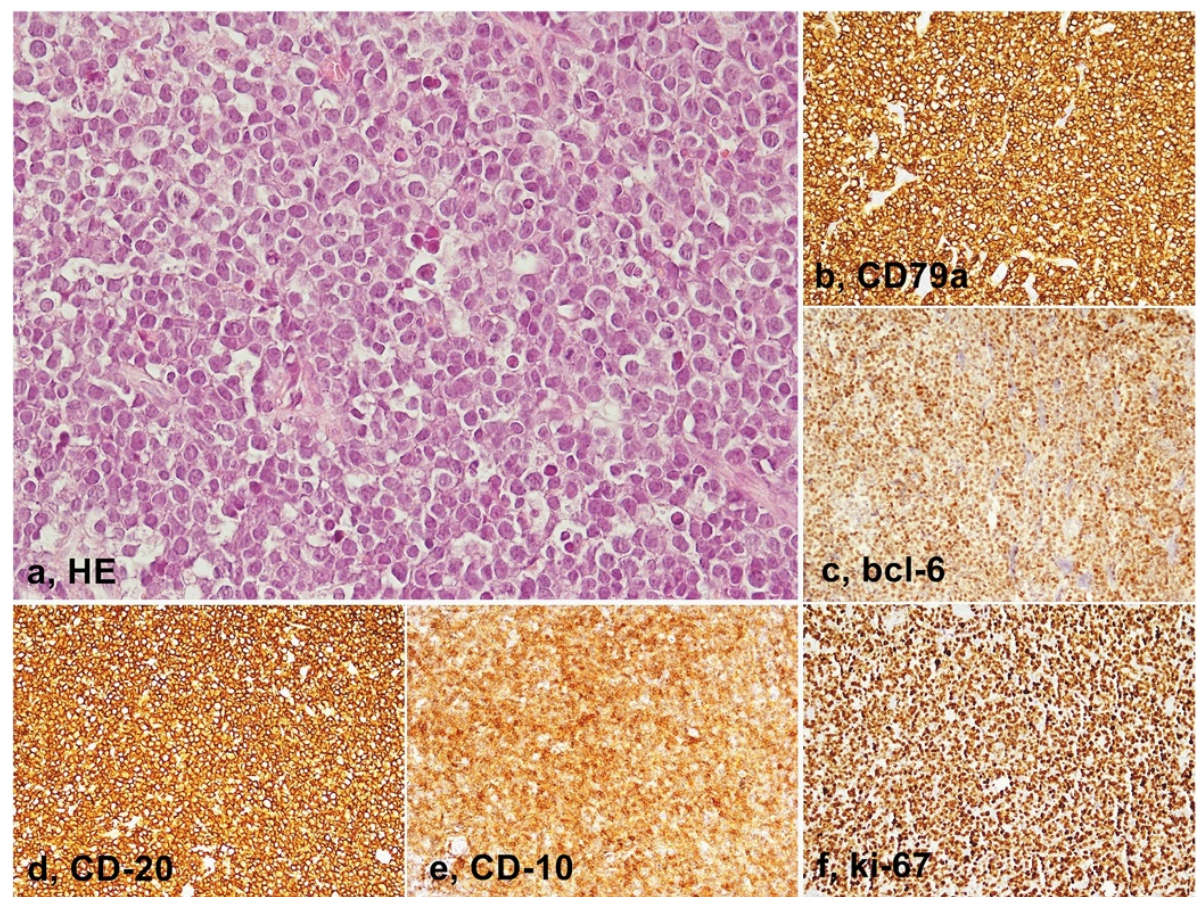

Figure 2 Burkitt's lymphoma of the adult - Histopathology and immunohistochemistry. a, Medium sized lymphocytes with high mitotic index and macrophages with tingible bodies (Hematoxylin-Eosin, 40x); b, CD79a expression; c, bcl6 expression; d, CD 20 expression; e, CD 10 expression; f, Ki- 67 expression (LSAB-HRP, nuclear counterstaining with type II Gill's Hematoxylin).

Moreover, one of the studied patients was surely immunodeficient.

In the children subgroup LMP-1 was detected in 34 cases, 17 positively staining for the marker $(50 \%)$. Overall LMP-1 was positive in $18 / 38$ cases $(47.4 \%)$ and negative in 20/38 (52.6\%). We considered as positive cases with any percent of stained cells. The percentage of stained cells ranged from focal to more than $70 \%$ of lymphomatous cells.

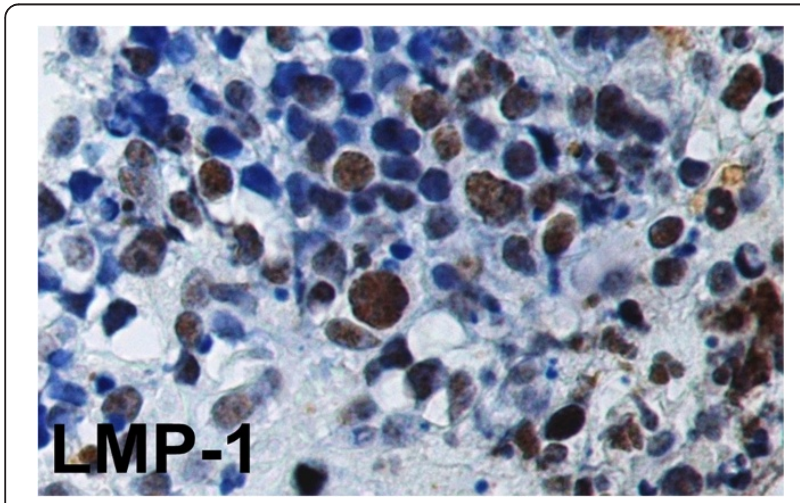

Figure 3 Immunohistochemical expression of LMP-1 in Burkitt's lymphoma. Note the strong nuclear staining of EBV-infected cells. (LSAB-HRP, x400; nuclear counterstaining with type ॥ Gill's Haematoxylin).
Considering ISH for EBER detection results:

- 1 out $2(50 \%)$ adult analyzed cases was positive, with $50 \%$ of stained tumor cells (this patient was a 22 years old female, coming from Napoli);

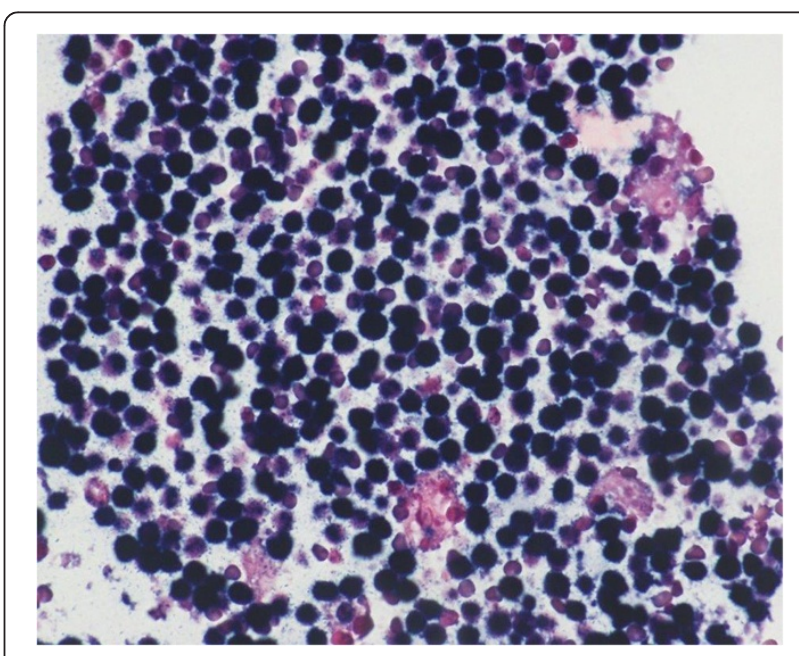

Figure 4 In situ hybridization for EBER in Burkitt's lymphoma. Note diffuse and strong staining showing early RNA transcripts of EBV accumulated in the nucleus of EBV-infected cells (Ventana ${ }^{\circledR}$ EBER ISH iView Blue Plus Kit; original magnification x200), 
- 15 out 24 (62.5\%) children analyzed Burkitt's lymphomas resulted as positive for EBER;

- the overall positivity has been observed in 16/26 Burkitt's lymphomas (61.53\%).

In children group of Burkitt's lymphoma, only in 23 cases we have been able to compare IHC results with ISH findings. As diagnostic test, IHC has shown a sensibility of $28.57 \%$, a specificity of $55.5 \%$, a PPV of $50 \%$, a NPV of $33.3 \%$ and an accuracy of $39.13 \%$. We have observed a positive concordance IHC-ISH in $17.39 \%$ of cases, and a negative one in $21.73 \%$. The total observed concordance was $39.13 \%$, the expected concordance was $10 \%$. The k coefficient was good (0.32).

Our study has demonstrated that although IHC is a good prognostic indicator when used in combination with molecular methods, it is not satisfactory when evaluated as detecting test as used alone. Adding ISH for EBER has the advantage to preserve the morphological context of signals in FFPE samples and increased the sensitivity of diagnostic EBV detection.

\section{Competing interests}

The authors declare that they have no competing interests.

\section{Authors' contributions}

GP has designed and conducted the study in all its phases; MCP and SC, carried out the immunohistochemical and molecular genetic studies; GA, AS and MP drafted the manuscript; RZ, MP, PS, MEE, VD and RF carried out the initial diagnosis and control diagnosis; $A D C, \mathrm{~PB}^{6}, \mathrm{~EB}, \mathrm{AS}$, and $\mathrm{PB}^{1,9}$ participated in writing the manuscript and text sequences' alignment; in the end, $\mathrm{PB}^{1,9}$ has revised it critically for important intellectual content. All authors read and approved the final manuscript.

\section{Author details}

${ }^{1}$ Department of Clinical and Experimental Medicine, Institute of Pathological Anatomy, University of Foggia, Foggia, Italy. ${ }^{2}$ Section of Pathological Anatomy Ospedale di Ascoli, Ascoli Piceno, Italy. ${ }^{3}$ Section of Pathological Anatomy, Ospedale dei Colli - Monaldi, Napoli, Italy. ${ }^{4}$ Section of Pathological Anatomy, Paediatric Oncological Hospital Pausillipon, Naples, Italy. ${ }^{5}$ Pathology Unit Istituto Nazionale dei Tumori, Naples, Italy. ${ }^{6}$ Department of Odontostomatological and Maxillofacial Sciences, University of Napoli 'Federico II', Naples, Italy. ${ }^{7}$ Department of Laboratory, Institute of Histopathology and Diagnostic Cytopathology, Fondazione di Ricerca e Cura 'Giovanni Paolo II'-UCSC, Campobasso, Italy. ${ }^{8}$ Piazza Attilio Omodei Zorini, 48, int.6 00166, Rome, RM, Italy. ${ }^{9}$ IRCCS CROB - Basilicata Cancer Institute, Rionero in Vulture, Potenza, Italy.

Received: 18 June 2013 Accepted: 28 September 2014

Published: 15 October 2014

\section{References}

1. Durand-Panteix S, Farhat M, Youlyouz-Marfak I, Rouaud P, Ouk-Martin C, David A, Faumont N, Feuillard J, Jayat-Vignoles C: B7-H1, which represses EBV-immortalized B cell killing by autologous T and NK cells, is oppositely regulated by C-Myc and EBV latency III program at both mRNA and secretory lysosome levels. J Immunol 2012, 189:181-190.

2. Ocheni $\mathrm{S}$, Olusina DB, Oyekunle AA, Ibegbulam O, Kröger N, Bacher $U$, Zander AR: EBV-Associated Malignancies. The Open Infectious Dis J 2010, 4:101-112.

3. Tao Q, Robertson KD, Manns A, Hildesheim A, Ambinder RF: Epstein-Barr virus (EBV) in endemic Burkitt's lymphoma: molecular analysis of primary tumor tissue. Blood 1998, 91(4):1373-1381. Erratum in: Blood 1998 Apr 15;91(8):3091.

4. Wright DH: Burkitt's lymphoma: a review of the pathology, immunology, and possible etiologic factors. Pathol Annu 1971, 6:337-363.
5. de Thé G, Geser A, Day NE, Tukei PM, Williams EH, Beri DP, Smith PG, Dean AG, Bronkamm GW, Feorino P, Henle W: Epidemiological evidence for causal relationship between Epstein-Barr virus and Burkitt's lymphoma from Ugandan prospective study. Nature 1978, 274(5673):756-761.

6. Crawford DH: Biology and disease associations of Epstein-Barr virus. Philos Trans R Soc Lond B Biol Sci 2001, 356461-356473.

7. Andreone P, Gramenzi A, Lorenzini S, Biselli M, Cusaro C, Pileri S, Bernardi M: Posttransplantation lymphoproliferative disorders. Arch Intern Med 2003, 163:1997-2004.

8. Holman CJ, Karger AB, Mullan BD, Brundage RC, Balfour HH Jr: Quantitative Epstein-Barr virus shedding and its correlation with the risk of post-transplant lymphoproliferative disorder. Clin Transplant 2012, 26:741-747.

9. Merlino C, Cavallo R, Bergallo M, Giacchino F, Bollero C, Negro Ponzi A, Cavallo G: Epstein-Barr viral load monitoring by quantitative $P C R$ in renal transplant patients. New Microbiol 2003, 26:141-149.

10. Orii T, Ohkohchi N, Kikuchi H, Koyamada N, Chubachi S, Satomi S, Kimura H, Hoshino Y, Morita M: Usefulness of quantitative real-time polymerase chain reaction in following up patients with Epstein-Barr virus infection after liver transplantation. Clin Transplant 2000, 14(4 Pt 1):308-317.

11. Niedobitek G: Epstein-Barr virus infection in the pathogenesis ofnasopharyngeal carcinoma. J Clin Pathol Mol Pathol 2000, 53:248-254.

12. Sousa H, Pinto-Correia AL, Medeiros R, Dinis-Ribeiro M: Epstein-Barr virus is associated with gastric carcinoma: The question is what is the significance? World J Gastroenterol 2008K, 14:4347-4351.

13. Hecht JL, Aster JC: Molecular biology of Burkitt's lymphoma. J Clin Oncol 2000, 18:3707-3721.

14. Wright DH: The epidemiology of Burkitt's tumor. Cancer Res 1967, 27:2424-2438.

15. Thorley-Lawson DA: Epstein-Barr virus: exploiting the immune system. Nat Rev Immunol 2001, 1:75-82.

16. Henle W, Henle G: The Epstein-Barr Virus. Berlin: Springer; 1979:61-78.

17. Kelly G, Bell A, Rickinson A: Epstein-Barr virus-associated Burkitt lymphomagenesis selects for downregulation of the nuclear antigen EBNA2. Nat Med 2002, 8:1098-1104.

18. Niedobitek $G$, Agathanggelou A, Rowe $M$, Jones EL, Jones DB, Turyaguma $P$, Oryema J, Wright DH, Young LS: Heterogeneous expression of Epstein-Barr virus latent proteins in endemic Burkitt's lymphoma. Blood 1995, 86:659-665.

19. Brady G, MacArthur GJ, Farrell PJ: Epstein-Barr virus and Burkitt lymphoma. J Clin Pathol 2007, 60:1397-1402.

20. Bieging KT, Swanson-Mungerson M, Amick AC, Longnecker R: Epstein-Barr Virus in Burkitt's Lymphoma: a role for Latent Membrane Protein 2A. Cell Cycle 2010, 9(5):901-908.

21. Magrath I: Epidemiology: clues to the pathogenesis of Burkitt lymphoma. BrJ Haematol 2012, 156(6):744-756.

22. Burkitt DP, Nelson CL, Williams EH: Some geographical variations in disease pattern in East and Central Africa. East Afr Med J 1963, 40:1-6.

23. Morton LM, Wang SS, Devesa SS, Hartge P, Weisenburger DD, Linet MS: Lymphoma incidence patterns by WHO subtype in the United States, 1992-2001. Blood 2006, 107:265.

24. Sant M, Allemani C, Tereanu C, De Angelis R, Capocaccia R, Visser O, Marcos-Gragera R, Maynadié M, Simonetti A, Lutz JM, Berrino F: Incidence of hematologic malignancies in Europe by morphologic subtype: results of the HAEMACARE project. Blood 2010, 116:3724-3734.

25. Swerdlow SH, Campo E, Harris NL, Jaffe ES, Pileri SA, Stein H, Thiele J, Vardiman JW: World Health Organization Classification of Tumours of Haematopoietic and Lymphoid Tissues. Lyon: IARC Press; 2008.

26. Boerma EG, van Imhoff GW, Appel IM, Veeger NJ, Kluin PM, Kluin-Nelemans $J C$ : Gender and age-related differences in Burkitt lymphoma epidemiological and clinical data from The Netherlands. Eur J Cancer 2004, 40:2781.

27. Magrath IT, Sariban E: Clinical features of Burkitt's lymphoma in the USA. IARC Sci Publ 1985, 60:119-127.

28. Guech-Ongey M, Simard EP, Anderson WF, Engels EA, Bhatia K, Devesa SS, Mbulaiteye SM: AIDS-related Burkitt lymphoma in the United States: what do age and CD4 lymphocyte patterns tell us about etiology and/or biology? Blood 2010, 116:5600.

29. Raphael M, Gentilhomme O, Tulliez M, Byron PA, Diebold J: Histopathologic features of high grade non-Hodgkin's lymphomas in acquired immunodeficiency syndrome. The French Study group of Pathology for 
Human Immunodeficiency Virus-Associated Tunors. Arch Pathol Lab Med 1991, 115:15-20.

30. Cardy AH, Sharp L, Little J: Burkitt's Lymphoma: A Review of the Epidemiology. Kuwait Med J 2001, 33(4):293-306.

31. Burkitt DP: Determining the climatic limitations of a children's cancer common in Africa. Br Med J 1962, 2:1019-1023.

32. Burkitt DP: Discovering Burkitt's lymphoma. In Epstein-Barr Virus and Human Disease. Edited by Levine PH, Ablashi DV, Nonoyana M, Pearson GR, Clifton GR. New Jersey: Humana Press Incorporated; 1989.

33. Khanna $R$, Burrows SR, Moss DJ: Immune regulation in Epstein-Barr virus-associated diseases. Microbiol Rev 1995, 59:387-405.

34. Rickinson AB, Kieff E: Epstein-Barr virus. In Field's Virology. Edited by Fields BN, Knipe DM, Howley PM, Chanock RM, Melnick JL, Monath TP, Roizman B, Straus SE. Philadelphia, P.A: Lippincott-Raven; 1996:2397-2446.

35. Magrath IT: African Burkitt's lymphoma: histology, biology, clinical features, and treatment. Am J Pediatr Hematol Oncol 1991, 13:222-246.

36. Hummel M, Anagnostopoulos I, Korbjuhn P, Stein H: Epstein-Barr virus in B-cell non- Hodgkin's lymphomas: unexpected infection patterns and different infection incidence in low- and high-grade types. J Pathol 1995, 175:263-271.

37. Shapira J, Peylan-Ramu N: Burkitt's lymphoma. Oral Oncol 1998, 34:15-23.

38. Leder P, Battey J, Lenoir G, Moulding C, Murphy W, Potter H, Stewart T, Taub R: Translocations among antibody genes in human cancer. Science 1983, 222:765-771.

39. Klein $\mathrm{G}$, Klein $\mathrm{E}:$ Myc/lg juxtaposition by chromosomal translocations: some new insights, puzzles and paradoxes. Immunol Today 1985 , 6:208-215.

40. Dalla-Favera R, Martinotti S, Gallo RC, Erickson J, Croce CM: Translocation and rearrangements of the c-myc oncogene locus in human undiff e rentiated B-cell lymphomas. Science 1983, 219:963-967.

41. Pelicci P, Knowles DM, Magrath I, Dalla-Favera R: Chromosomal breakpoints and structural alterations of the c-myc locus differ in endemic and sporadic forms of Burkitt lymphoma. Proc Natl Acad Sci U S A 1986, 83:2984.

42. Dalla-Favera GG: R. Molecular pathogenesis of AIDS-related lymphomas. Adv Cancer Res 1995, 67:113-153.

43. Love C, Sun Z, Jima D, Li G, Zhang J, Miles R, Richards KL, Dunphy CH, Choi WWL, Srivastava G, Lugar PL, Rizzieri DA, Lagoo AS, Bernal-Mizrachi L, Mann KP, Flowers CR, Naresh KN, Evens AM, Chadburn A, Gordon LI, Czader MB, Gill Jl, His ED, Greenough A, Moffitt AB, McKinney M, Banerjee A, Grubor V, Levy S, Dunson DB, et al: The genetic landscape of mutations in Burkitt lymphoma. Nat Genet 2012, 44(12):1321-1325.

44. Diebold J: Burkitt lymphoma. In Pathology and Genetics of Tumours of Haematopoietic and Lymphoid Tissues. Edited by Jaffe E, Harris N, Stein H, Vardiman JW. Washington, DC: IARC Press; 2001:181-184.

45. Blum KA, Lozanski G, Byrd JC: Adult Burkitt leukemia and lymphoma. Blood 2004, 104:3009-3020

46. Patte C, Auperin A, Michon J, Behrendt H, Leverger G, Frappaz D, Lutz P Coze C, Perel Y, Raphaël M, Terrier-Lacombe MJ, Société Française d'Oncologie Pédiatrique: The Societe Francaise d'Oncologie Pediatrique LMB89 protocol: highly effective multiagent chemotherapy tailored to the tumor burden and initial response in 561 unselected children with B-cell lymphomas and L3 leukemia. Blood 2001, 97:3370-3379.

47. Bowman WP, Shuster JJ, Cook B, Griffin T, Behm F, Pullen J, Link M, Head D, Carroll A, Berard C, Murphy S: Improved survival for children with B-cell acute lymphoblastic leukemia and stage IV small non-cleaved-cell lymphoma: a Pediatric Oncology Group study. J Clin Oncol 1996, 14:1252-1261.

48. Magrath I, Adde M, Shad A, Venzon D, Seibel N, Gootenberg J, Neely J, Arndt C, Nieder M, Jaffe E, Wittes RA, Horak ID: Adults and children with small non-cleaved-cell lymphoma have similar excellent outcome when treated with the same chemotherapy regimen. J Clin Oncol 1996, 14:925-934.

49. Nakamura N, Nakamine H, Tamaru J, Nakamura S, Yoshino T, Ohshima K, Abe M: Thedistinction between Burkitt lymphoma and diffuse large B-cell lymphoma with cmyc rearrangement. Mod Pathol 2002, 15:771-776

50. Haralambieva E, Boerma EJ, van Imhoff GW, Rosati S, Schuuring E, MüllerHermelink HK, Kluin PM, Ott G: Clinical, immunophenotypic, and genetic analysis of adult lymphomas with morphologic features of Burkitt lymphoma. Am J Surg Pathol 2005, 29:1086-1094.
51. Frost M, Newell J, Lones MA, Tripp SR, Cairo MS, Perkins SL: Comparative immunohistochemical analysis of pediatric Burkitt lymphoma and diffuse large B-cell lymphoma. Am J Clin Pathol 2004, 121:384-392.

52. Lenze $D$, Leoncini L, Hummel M, Volinia S, Liu CG, Amato T, De Falco G, Githanga J, Horn H, Nyagol J, Ott G, Palatini J, Pfreundschuh M, Rogena E, Rosenwald A, Siebert $\mathrm{R}$, Croce $\mathrm{CM}$, Stein $\mathrm{H}$ : The different epidemiologic subtypes of Burkitt lymphoma share a homogenous micro RNA profile distinct from diffuse large B-cell lymphoma. Leukemia 2011, 25:1869-1876.

53. Gulley ML, Glaser SL, Craig FE, Borowitz M, Mann RB, Shema SJ, Ambinder RF: Guidelines for Interpreting EBER In Situ Hybridization and LMP1 Immunohistochemical Tests for Detecting Epstein-Barr Virus in Hodgkin Lymphoma. Am J Clin Pathol 2002, 117:259-267.

54. Khan G, Miyashita EM, Yang B, Babcock GJ, Thorley-Lawson DA: Is EBV persistence in vivo a model for B cell homeostasis? Immunity 1996, 5:173-179.

55. MacMahon EME, Ambinder RF: EBER in situ hybridisation: Sensitive detection of latent Epstein-Barr virus in individual cells. Rev Med Virol 1994, 4:251-260

56. Gulley ML: Molecular Diagnosis of Epstein-Barr Virus-Related Diseases. J Mol Diagn 2001, 3(1):1-9.

doi:10.1186/1750-9378-9-34

Cite this article as: Pannone et al:: The role of EBV in the pathogenesis of Burkitt's Lymphoma: an Italian hospital based survey. Infectious Agents and Cancer 2014 9:34.

\section{Submit your next manuscript to BioMed Central and take full advantage of:}

- Convenient online submission

- Thorough peer review

- No space constraints or color figure charges

- Immediate publication on acceptance

- Inclusion in PubMed, CAS, Scopus and Google Scholar

- Research which is freely available for redistribution 